\section{Unrelated cord blood transplantation and post-transplant cyclophosphamide}

The number of unrelated cord blood transplants (UCBT) are declining in Europe,${ }^{1}$ despite comparable outcome with grafts using unrelated donor peripheral blood or bone marrow. ${ }^{2}$ The reasons for the decline may be due to the well-known slow engraftment and delayed immune reconstitution of UCBT, which may result in a significant risk of infections and non-relapse mortality (NRM). ${ }^{3,4}$

Neutrophil and platelet recovery can be shortened by direct intra-bone injection of $\mathrm{CB}$ cells, ${ }^{5}$ but immune recovery remains an issue, especially when anti-thymocyte globulin (ATG) is used in the conditioning regimen. ${ }^{5}$ In the absence of ATG, grade III-IV acute graft versus host disease $(\mathrm{GvHD})$ is reported to be $21 \%{ }^{6}$ and when ATG is added in the transplant platform, GvHD is reduced $(15 \%),{ }^{6}$ but immune reconstitution is delayed, leading to infectious complications, and late viral infections. ${ }^{4,7,8}$ The crucial role of ATG and the risk of over or under exposure is further proven by the attempt to optimize ATG dose based on lymphocyte counts, rather than patient's weight, ${ }^{9}$ and by carefully assessing the speed of CD4 recovery according to ATG dosing pre-transplant. ${ }^{10}$ An additional reason for the decline in numbers of UCBT is the competition of HLA haploidentical transplants (HAPLO), ${ }^{11}$ especially performed with post-transplant cyclophosphamide (PT-CY), as first described by the Baltimore group. ${ }^{12}$ We have been particularly impressed with the speed of immune recovery of HAPLO transplants with PT-CY, ${ }^{13}$ with median CD4 counts on day +100 $(190 / \mu \mathrm{l})$ comparable to CD4 counts after HLA identical sibling grafts $(229 / \mu \mathrm{l})$, and significantly higher as compared to unrelated and cord blood grafts receiving ATG for GvHD prophylaxis. ${ }^{13}$

We therefore hypothesized that PT-CY would be an effective GvHD prophylaxis regimen for patients undergoing an UCBT and, by preventing GvHD in the absence of ATG, hematologic and immune recovery could be accelerated, as seen in the HAPLO setting. We are now reporting a first case.

The patient, a 42-year-old female, was diagnosed with acute myeloid leukemia (AML) NPM1 ${ }^{+}$in December 2015 with normal cytogenetics; she was induced and achieved a complete hematologic and NPM1 negative remission. The patient relapsed in june 2017 and was re-induced to a complete remission with anthracycline and cytosine arabinoside. A 5/6 UCB unit was identified with a cell count of $4.2 \times 10^{7} / \mathrm{kg}$. On high resolution, the UCB unit and the patient were mismatched at the A locus (24:03 vs. 24:02), at the B locus (18:01 vs. 38:01), and they were DRB1 allelic matched. There was a gender mismatch ( $M$ $\rightarrow \mathrm{F})$ and $\mathrm{ABO}$ mismatch $(\mathrm{B}+\rightarrow 0+$ ). In November 2017, she was prepared with a conditioning regimen including thiotepa $5 \mathrm{mg} / \mathrm{kg}$ on days -6 and -5 , fludarabine 50 $\mathrm{mg} / \mathrm{m}^{2}$ on days -4-3-2 and intravenous busulfan 3.2 $\mathrm{mg} / \mathrm{kg}$ on days -4-3-2 (Figure 1). On 14.11.2017 she received a single UCB unit. GvHD prophylaxis consisted of intravenous cyclosporine (CsA) $3 \mathrm{mg} / \mathrm{kg}$ starting on day 0 , mycophenolate $(\mathrm{MMF}) 2$ gr/day starting on day+1, and PT-CY $30 \mathrm{mg} / \mathrm{kg}$ on days +3 and +5 . CsA was switched to oral administration on day +20 .

Hematologic recovery: the patient achieved a neutrophil count of $0.5 \times 10^{9} / \mathrm{L}$ on day +15 and a platelet count of $20 \times 10^{9} / \mathrm{L}$ on day 21 ; platelet counts were 73 and 179 on days +50 and +100 , respectively (Figure 2); chimerism was full donor, by FISH (Y probe) and

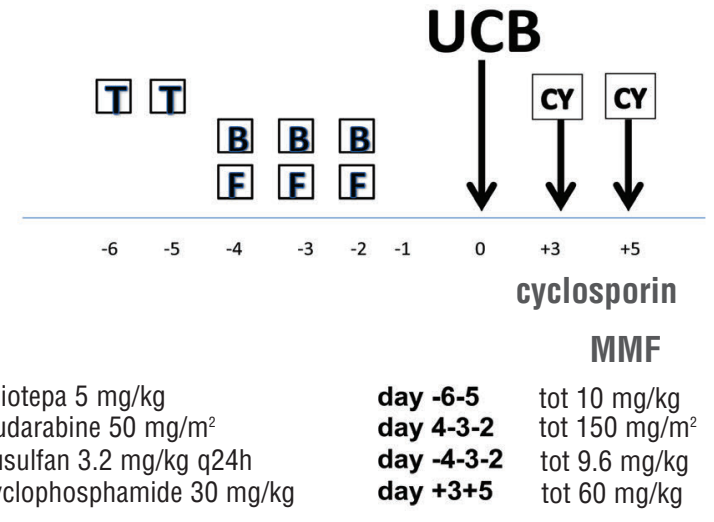

Figure 1 Conditioning regimen and GvHD prophylaxis. T: thiotepa; B:busulfan; F: fludarabine; CY: cyclophosphamide; MMF: mycophenolate; cyclophosphamide $(\mathrm{CY})$ is given on day +3 and $+5(30 \mathrm{mg} / \mathrm{kg})$ and cyclosporine is started on day 0 , and mycophenolate on day +1 .

microsatellites, from the first evaluation on day +30 (Figure 2). ABO blood group conversion was complete by day +100 . The patient was discharged on day +25 , then readmitted on day +32 for 6 days due to fever and a flu. She has not since been readmitted to hospital. Grade I skin GvHD developed on day +20 and was not treated.

Immune recovery: there was a rapid increase of NK cells up to $326 / \mu 1$ on day +29 , followed by a decline of $\mathrm{NK}$ cells and a rise in $\mathrm{CD}^{+}$cells. Absolute CD 4 and CD 8 counts on days $+50,+100$ and +180 were 63 and $96 / \mu 1$, 92 and $98 / \mu 1$, and 150 and $220 / \mu 1$, respectively. Her current counts on day +302 are CD4 885/ $\mu 1$, CD8 1115/ $\mu 1$ and NK $575 / \mu 1$.The patient is alive and well, NPM1 negative 10 months post UCB.

Hematologic recovery has been a long-standing issue of $\mathrm{CB}$ transplants. In a conventional $\mathrm{CB}$ transplant, with or without ATG, the median neutrophil and platelet recovery is 24 and 58 days, respectively. ${ }^{14}$ Similarly, neutrophil recovery is reported to occur on day 23 and 21 for single and double $C B$ transplants, with platelet recovery occurring on day 58 and $85 .{ }^{15}$ Intra-bone infusion of CB cells has been shown to accelerate platelet recovery in one report (day 36$)^{5}$ and neutrophil recovery in another report (day 15$)^{16}$ : in the latter, however, platelet recovery remains at a median of 45 days. ${ }^{16}$ Expansion of CB units is another strategy studied to improve hematologic and immune recovery: with the infusion of two $\mathrm{CB}$ units, one of which ex vivo expanded, the neutrophil recovery is accelerated to day 15 , but platelet recovery remains at day $33 .{ }^{17}$ The present case compares favorably with these data with a rapid recovery of both neutrophils (day +15$)$ and platelets (day +21$)$.

Immune recovery is the other crucial issue: Admiral and coworkers have shown that the probability of T-cell recovery (>50 $\mathrm{CD}^{+} \mathrm{T}$ cells/ $\mu \mathrm{l}$ within 100 days) was decreased even in the lowest ATG exposure group after unrelated $\mathrm{CB}$ transplant, while only the highest ATG exposure group after $\mathrm{BM} / \mathrm{PB}$ grafts had poor T-cell recovery. ${ }^{18}$ This patient clearly met the criteria for rapid CD4 recovery (>50 CD4 ${ }^{+} \mathrm{T}$ cells/ $\mu \mathrm{l}$ within day 100 ), and the lack of viral infections would confirm the strength of immune reconstitution. However, more patients will be needed to confirm this result.

In conclusion, this first patient suggests that UCB transplantation can be performed, following a myeloablative conditioning regimen, with $\mathrm{CsA}, \mathrm{MMF}$ and PT-CY 
for GvHD prophylaxis. Hematologic recovery as well as immune reconstitution were both fast, with no infectious complications, and no GvHD. A prospective trial has been activated to assess whether this encouraging first case can be confirmed.

Andrea Bacigalupo, Simona Sica, Luca Laurenti, Federica Sora', Sabrina Giammarco, Elisabetta Metafuni, Idanna Innocenti, Francesco Autore, Luciana Teofili, Maria Bianchi and Patrizia Chiusolo

Istituto di Ematologia, Fondazione Policlinico Universitario A

Gemelli IRCCS, Universita' Cattolica, Rome, Italy

Funding: this study was supported by FARITMO Genova, Italy.

Correspondence:apbacigalupo@yahoo.com

doi:10.3324/haematol.2018.202598

Information on authorship, contributions, and financial \& other disclosures was provided by the authors and is available with the online version of this article at www. haematologica.org.

\section{References}

1. Passweg. JR, Baldomero H, Gratwohl A, et al. and for the European Group for Blood and Marrow Transplantation (EBMT). The EBMT activity survey: 1990-2010. Bone Marrow Transplant. 2012; 47(7):906-923.

2. Baron F, Ruggeri A, Beohou E, et al. RIC versus MAC UCBT in adults with AML: A report from Eurocord, the ALWP and the CTIWP of the EBMT. Oncotarget. 2016;7(28):43027-43038.

3. Danby R, Rocha V. Improving engraftment and immune reconstitution in umbilical cord blood transplantation. Front Immunol. 2014; 5:68.

4. de Koning C, Admiraal R, Nierkens S, Boelens JJ. Immune reconstitution and outcomes after conditioning with anti-thymocyte-globulin in unrelated cord blood transplantation; the good, the bad, and the ugly. Stem Cell Investig. 2017;4:38.

5. Frassoni F, Gulandi F, Podestà M, et al. Direct intrabone transplant of unrelated cord-blood cells in acute leukaemia: a phase I/II study. Lancet Oncol. 2008;9(9):831-839.

6. Chen YB, Wang T, Hemmer MT, et al. GvHD after umbilical cord blood transplantation for acute leukemia: an analysis of risk factors and effect on outcomes. Bone Marrow Transplant. 2017;52(3):400408

7. Paviglianiti A, Dalle JH, Ayas M, et al. Low body mass index is associated with increased risk of acute GvHD after umbilical cord blood transplantation in children and young adults with acute leukemia: a study on behalf of Eurocord and the EBMT Pediatric Disease Working Party. Biol Blood Marrow Transplant. 2018;24(4):799-805.

8. Barn F, Ruggeri A, Beohou E, et al. Single- or double-unit UCBT following RIC in adults with AL: a report from Eurocord, the ALWP and the CTIWP of the EBMT. J Hematol Oncol. 2017;10(1):128.

9. Admiral R, Nierkens S, de Witte MA, et al. Association between antithymphocyte globulin exposure and survival outcomes in adult unrelated hemopoietic cell transplantation: a multicenter, retrospective, pharmakodynamic analysis. Lancet Haematol. 2017;4(4):e183-e191.

10. Admiral R, Lindemans CA, Van Kesteren C, et al. Excellent T cell reconstitution and survival depends on low ATG exposure after pediatric cord blood transplantation. Blood. 2016;128(23):2734-2741.
Platelet recovery after UCB TX with PTCY

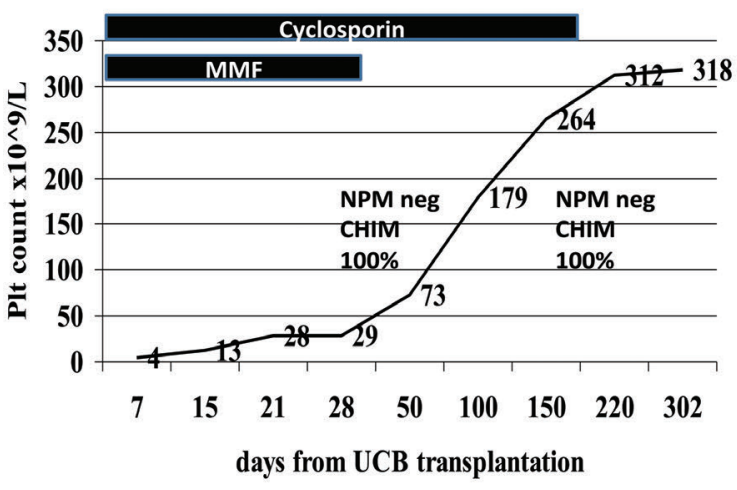

Figure 2. Platelet recovery in this patient, duration of GvHD prophylaxis and timing of full donor chimerism and NPM1 negativity.

11. Passweg JR, Baldomero H, Bader $\mathrm{P}$, et al. Use of haploidentical stem cell transplantation continues to increase: the 2015 European Society for Blood and Marrow Transplant activity survey report. Bone Marrow Transplant. 2017;52(6):811-817.

12. Luznik L, O’Donnell PV, Simons HJ, et al. HLA-Haploidentical bone marrow transplantation for hematological malignancies using nonmyeloablative conditioning regimen and high dose, posttransplantation cyclophosphamide. Biol Blood Marrow Transplant. 2008; 14(6):641-650.

13. Raiola AM, Dominietto A, di Grazia C, et al. Unmanipulated haploidentical transplants compared with other alternative donors and matched sibling grafts. Biol Blood Marrow Transplant. 2014; 20(10):1573-1579

14. Michel G, Galambrun C, Sirvent A, et al. Single- vs double-unit cord blood transplantation for children and young adults with acute leukemia or myelodysplastic syndrome. Blood. 2016;127(26):34503457.

15. Wagner JE, Eapen M, Carter S, et al. One-unit versus two-unit cordblood transplantation for hematologic cancers. $N$ Engl J Med. 2014;371(18):1685-1694.

16. Kurita N, Gosho M, Yokoyama Y, et al. A phase I/II trial of intrabone marrow cord blood transplantation and comparison of the hematological recovery with the Japanese nationwide database Japanese experience. Bone Marrow Tranplant. 2017;52(4):574-579.

17. Mehta RS, Dave H, Bollard CM, et al. Engineering cord blood to improve engraftment after cord blood transplant. Stem Cell Investig. 2017;4:41.

18. Admiraal R, van Kesteren C, Jol-van der Zijde CM, et al. Association between anti-thymocyte globulin exposure and CD4+ immune reconstitution in paediatric haemopoietic cell transplantation: a multicentre, retrospective pharmacodynamic cohort analysis. Lancet Haematol. 2015;2(5):e194-203. 